\title{
Control Strategy for Selective Compensation of Power Quality Problems through Three-Phase Four-Wire UPQC
}

\author{
Yash Pal ${ }^{\dagger}$, A. Swarup*, and Bhim Singh** \\ $\dagger *$ Department of Electrical Engineering, National Institute of Technology, Kurukshetra, India \\ ** Department of Electrical Engineering, Indian Institute of Technology, New Delhi, India
}

\begin{abstract}
This paper presents a novel control strategy for selective compensation of power quality (PQ) problems, depending upon the limited rating of voltage source inverters (VSIs), through a unified power quality conditioner (UPQC) in a three-phase four-wire distribution system. The UPQC is realized by the integration of series and shunt active power filters (APFs) sharing a common dc bus capacitor. The shunt APF is realized using a three-phase, four-leg voltage source inverter (VSI), while a three-leg VSI is employed for the series APF of the three-phase four-wire UPQC. The proposed control scheme for the shunt APF, decomposes the load current into harmonic components generated by consumer and distorted utility. In addition to this, the positive and negative sequence fundamental frequency active components, the reactive components and harmonic components of load currents are decomposed in synchronous reference frame (SRF). The control scheme of the shunt APF performs with priority based schemes, which respects the limited rating of the VSI. For voltage harmonic mitigation, a control scheme based on SRF theory is employed for the series APF of the UPQC. The performance of the proposed control scheme of the UPQC is validated through simulations using MATLAB software with its Simulink and Power System Block set toolboxes.
\end{abstract}

Key Words: Current decomposition, Neutral current compensation, Selective compensation, Unified power quality conditioner (UPQC)

\section{INTRODUCTION}

Nowadays, Custom Power Devices (CPDs) [1], [2], which are applicable to distribution systems for enhancing reliability and quality of power, are gaining popularity. Custom power devices include static shunt compensator or distribution static compensator (D-STATCOM) [3] to compensate current based distortions and series static compensators or a dynamic voltage restorers (DVR) for the mitigation of voltage based distortions [4]. However, their capabilities are usually limited as they can only solve one or two power quality (PQ) problems. Recent research efforts have been made toward utilizing a device called UPQC to solve almost all PQ problems [5]. Generally CPDs are designed for full compensation irrespective of the priorities of consumers. Very few papers are reported in literature for the selective compensation of power quality problems using DSTATCOM [3], DVR [4] and UPQC/UCPC [5], [6]. The selective harmonic elimination method (SHEM) [3], selective voltage harmonic compensation scheme [4], harmonic selective UPQC based on multi variable regulator (MVR) [5] and UCPC

\footnotetext{
Manuscript received Nov. 13, 2010; revised Apr. 5, 2011

Recommended for publication by Associate Editor Kyo-Beum Lee.

$\dagger$ Corresponding Author: yash_pal1971@yahoo.com

Tel: +91-1744-233400, Fax: +91-1744-238050, N.I.T

* Dept. of Electrical Eng., National Institute of Technology, India

** Dept. of Electrical Eng., Indian Institute of Technology, India
}

with an array of resonant harmonic controllers [6] are some of the techniques used for selective compensation in CPDs. On the other hand, different topologies of APFs are reported in the literature for selective compensation. These topologies estimate the derived components based on $p-q$ theory [7], modified p-q theory [8], FBD theory [9], orthogonal decomposition [10], Lagrange multiplier-based decomposition [11], estimation based on neural networks [12], etc. Unfortunately, these control schemes utilizes complex calculations and most of them are not employed for undistorted mains conditions. Further, some schemes based on notch filter [11] and adaptive techniques [13] are used to compute the decompositions of current. Apart from this, methods based on frequency domain approach have been reported, which separate out the customer and supply side harmonic contributions [17], [18]. Also, a scheme based on current decomposition technique in time domain is also employed for selective compensation by a shunt APF [14]. An approach based on frequency domain approach is accurate but involves lot of computation, hence not suitable for on-line applications while, time domain approach is fast but limited to single node applications.

In this paper, the advantages of time and frequency domain approaches has been combined to obtain flexible control of current based distortions using a three-phase four-wire UPQC. The customer and supply side harmonic contributions are 


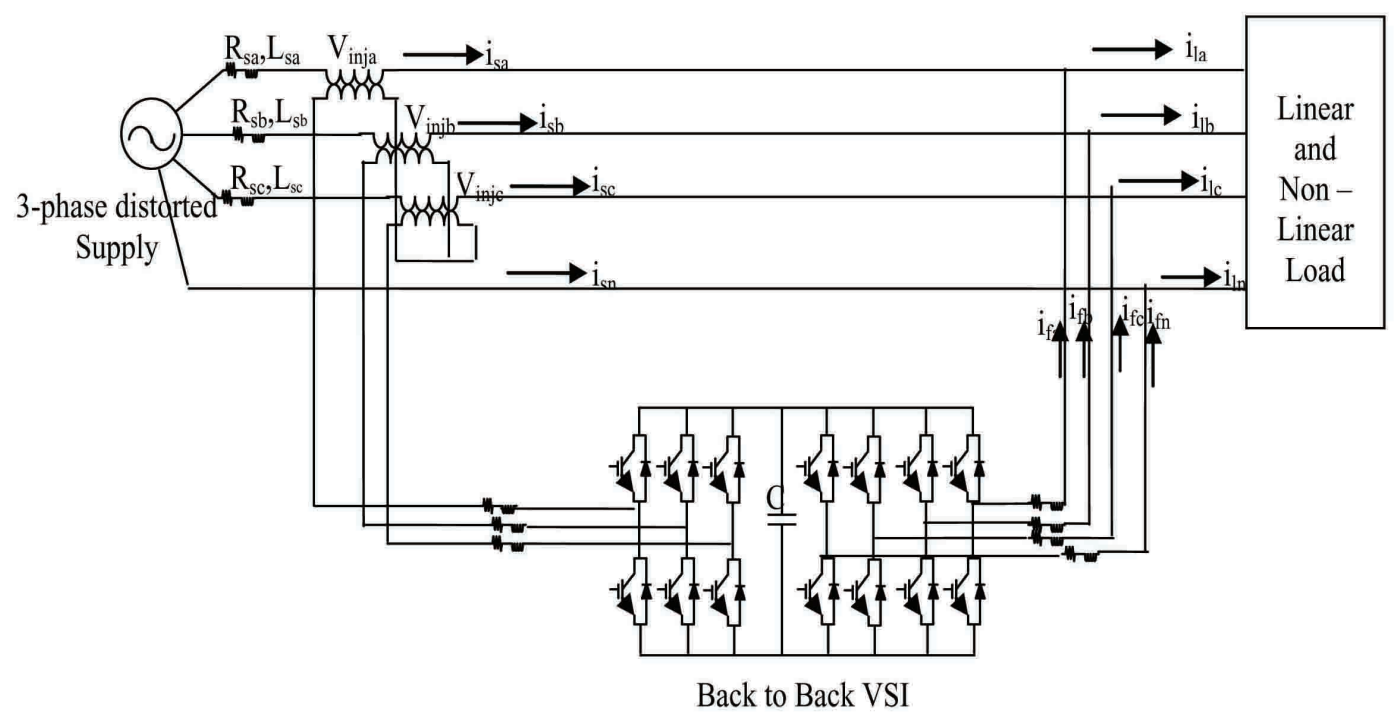

Fig. 1. Detailed Configuration of 3P-4WUPQC.

separate out based on the method proposed by Srinivasan [16] and in addition to this, a simple SRF-based scheme is used to decompose the load current into four parts [14]: positive sequence fundamental frequency active current $\left(i_{L R 1+}\right)$, positive sequence fundamental frequency reactive current $\left(i_{L X 1+}\right)$, current at harmonic frequencies $\left(i_{L h}\right)$ and the negative sequence fundamental frequency current $\left(i_{L 1-}\right)$. With these current components, the selective compensation of combinations of them can be made, which respects the limited rating of the shunt APF of three-phase four-wire UPQC and also attributes the responsibility of the customer and the utility at the point of common coupling. On the other hand, a simple control scheme based on SRF theory is used for the control of the series APF of the UPQC. In this proposed control scheme for UPQC, the current/voltage control is applied over the fundamental supply currents/voltages instead of fast changing APFs currents/voltages, there by reducing the computational delay. In addition to this, for the mitigation of source neutral current by the $4^{\text {th }}$ leg of the shunt APF VSI, the load or the filter neutral current is not sensed, thereby reducing the numbers of current sensors. The effectiveness and dynamics of the scheme with selective compensation under varying load conditions is demonstrated through simulated waveforms using SPS Matlab/Simulink enviournment.

\section{SYSTEM CONFIGURATION}

Fig. 1 shows a 3-phase, 4-wire UPQC connected to a power system feeding a combination of linear and non-linear loads. It consists of a three leg voltage controlled VSI used as a series APF and a four leg current controlled VSI used as a shunt APF. The dc link of both of these active filters is connected to a common dc link capacitor. The four-leg VSI based shunt active filter is capable of suppressing the harmonics in the source currents, load balancing and powerfactor correction. The fourth leg of the shunt VSI topology is used to compensate the source neutral current. The series filter is connected between the supply and load terminals using

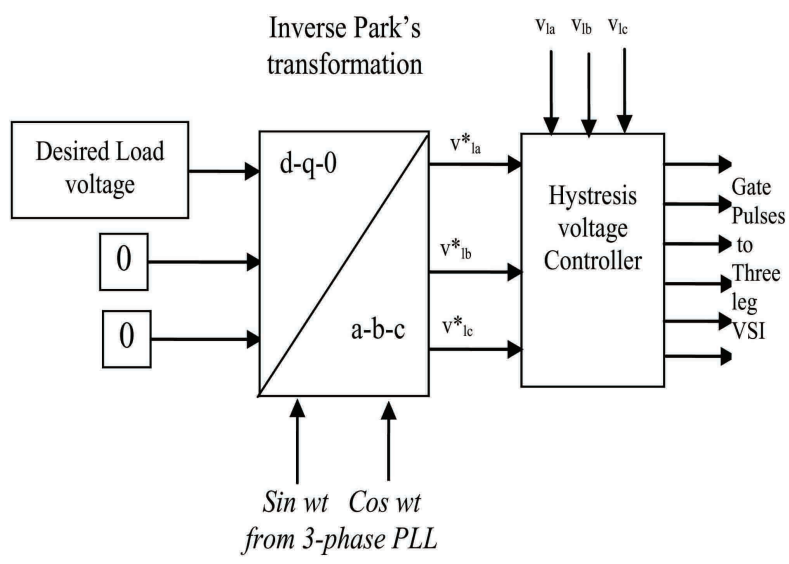

Fig. 2. Control Scheme of Series APF.

three single phase transformers with a turn's ratio of 5:1. The primary winding of these transformer are star connected and the secondary windings are connected in series with the three-phase supply. In addition to injecting the voltage, these transformers are used to filter the switching ripple content in the series active filter. A small capacity rated R-C filter is connected in parallel with the secondary of each series transformer to eliminate the high switching ripple content in the series active filter injected voltage. The VSIs for both the series and shunt APFs are implemented with IGBTs (Insulated Gate Bipolar Transistors). In Fig. $1\left(i_{s a}, i_{s b}, i_{s c}\right),\left(i_{l a}, i_{l b}\right.$, $\left.i_{l c}\right)$ and $\left(i_{f a}, i_{f b}, i_{f c},\right)$ represent the source currents, the load currents and the shunt APF currents in phase a, b and c, respectively. The source neutral current, load neutral current and shunt APF neutral current are represented by $i_{s n}, i_{l n}$ and $i_{f n}$, respectively. The injected voltages by the series APFs in phase $\mathrm{a}, \mathrm{b}$ and $\mathrm{c}$ are represented by $v_{\text {inja }}, v_{\text {injb }}$ and $v_{\text {injc }}$, respectively. The load under consideration is a combination of linear and non-linear type. The values of the circuit parameters and the loads under consideration are given in the Appendix. 


\section{Control Scheme of Series APF}

The proposed control strategy is aimed mainly at computing the three-phase reference voltages at the load terminal voltages $\left(v_{l a}^{*}, v_{l b}^{*}\right.$ and $\left.v_{l c}^{*}\right)$, which cancel out the distortions present in the supply voltages $\left(v_{s a}, v_{s b}\right.$ and $\left.v_{s c}\right)$ by injecting voltages $\left(v_{i n j a}\right.$, $v_{i n j b}$ and $\left.v_{i n j c}\right)$, thus making the voltage at PCC $\left(v_{l a}, v_{l b}\right.$ and $v_{l c}$ ) perfectly sinusoidal with a desired amplitude. In other words, the sum of the supply voltage and the injected series filter voltage makes the desired voltage at the load terminals.

The control strategy for the series APF is shown in Fig.2. Since the supply voltage is distorted, a phase locked loop (PLL) is used to achieve synchronization with the supply voltage [15]. Three-phase distorted supply voltages are sensed and given to PLL which generates two quadrature unit vectors $(\sin w t, \cos w t)$. The sensed supply voltage is multiplied by a suitable value of the gain before being given as an input to the PLL. A discrete three-phase PLL having minimum frequency $50 \mathrm{~Hz}$ at a sampling time of $50 \mu \mathrm{sec}$ is used here. A distortion free, balanced, constant magnitude three-phase voltage has ' $d$ ' components only, while the ' $\mathrm{q}$ ' and ' 0 ' components will be zero. Hence, with the help of the unit vectors $(\sin w t, \cos w t)$ obtained from the PLL, an inverse Parks transformation is done for the desired peak value of the PCC voltage (ie.325V) using eqn.(1) as:

$\left[\begin{array}{c}v_{l a}^{*} \\ v_{l b}^{*} \\ v_{l c}^{*}\end{array}\right]=\frac{2}{3}\left[\begin{array}{ccc}\cos \theta & -\sin \theta & 1 \\ \cos \left(\theta-\frac{2 \Pi}{3}\right) & -\sin \left(\theta-\frac{2 \Pi}{3}\right) & 1 \\ \cos \left(\theta+\frac{2 \Pi}{3}\right) & -\sin \left(\theta+\frac{2 \Pi}{3}\right) & 1\end{array}\right]\left[\begin{array}{c}v_{d} \\ 0 \\ 0\end{array}\right]$

All voltage regulation techniques are characterized by thier susceptibility to system changes, harmonic injection, switching frequency, practical implementation and dynamic performance. The hysteresis controller has been gaining much popularity among other techniques because of its robustness, simplicity of implementation and excellent dynamic performance [19]. Hence a hysteresis controller is used for the switching of series APF. The computed reference voltages from eqn.(1) are then given to the hysteresis controller along with the sensed three phase actual load voltages $\left(v_{l a}, v_{l b}\right.$ and $v_{l c}$ ). The output of the hysteresis controller is the switching signals to the six switches of the VSI of the series APF. The hysteresis controller generates the switching signals such that the voltage at the load terminals becomes perfectly sinusoidal with desired amplitude irrespective of harmonics present in supply voltages.

\section{Control Scheme of Shunt APF}

The control algorithm for the shunt APF depends on the decomposition scheme applied to the net load current, the priority of different power quality problems based on their individual weight-ages and the indirect control of the source current. In the following section the basic theory of the decomposition of the load current and the overall control schemes adopted for the selectivity of PQ components and indirect current control of shunt APF is explained in detail.

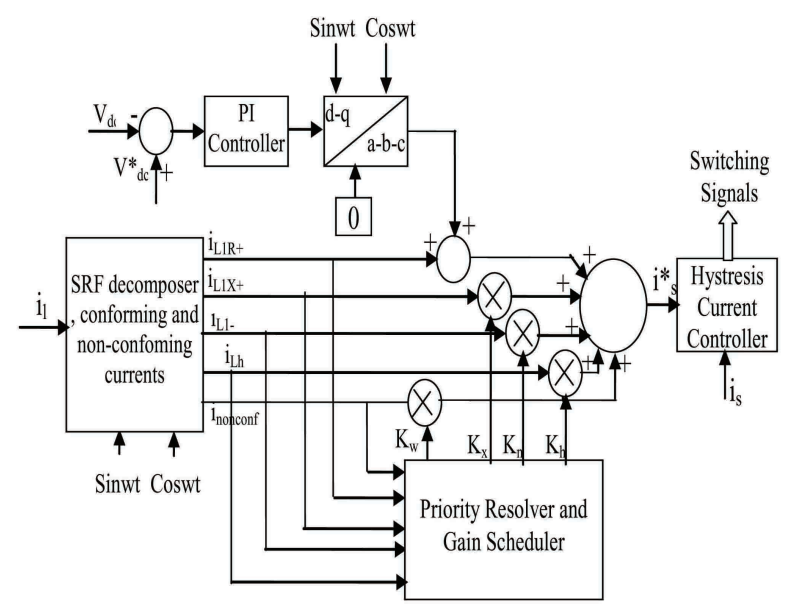

Fig. 3. Control Scheme of Shunt APF.

\section{A. Separation of Customer and Supply Side Harmonic Con- tributions [16]}

Each frequency component of the total of the total source current in a distorted supply system can be divided in two components. One is the conforming current and the other is the non-conforming current. The sum of all of the frequency components of the source current having a similar shape as that of the supply voltage is called the total conforming current. This is the current that customers should be allowed to draw from distorted utility voltages without any penalty. On the other hand, sum of all of the frequency a component that are produced by the consumer load, for a sinusoidal supply voltage, is called total non-conforming current, which the shunt APF of the UPQC should compensate.

As per the Fourier series a non-sinusoidal signal can be expressed as a sum of the sinusoidal signals of various frequencies. Based on this, the distorted utility voltage and load current can be expressed as:

$$
\begin{aligned}
& v_{s}(t)=\sum_{n=1}^{k} V_{n} \sin \left(n w t+\theta_{n}\right) \\
& i_{L}(t)=\sum_{n=1}^{k} I_{n} \sin \left(n w t+\phi_{n}\right)
\end{aligned}
$$

where $v_{S}(t)$ and $i_{L}(t)$ are the instantaneous source voltage and load current, $V_{n}$ and $I_{n}$ are the maximum voltage of nth-order utility voltage and load current, $\theta_{n}$ and $\Phi_{n}$ are the phase angle of the nth-order utility voltage and the load current, and $\mathrm{n}$ is the order of harmonics. The total conforming current drawn from the utility is the portion of the current, which retains the same level of distortion as the voltage. The conforming current should have the same graphical pattern of variation as the utility voltage. It might have a time lag or lead depending on the load under consideration. Thus, the fundamental frequency component of the conforming current will be equal to the fundamental frequency component of the load current. All other frequency components will be in the same proportion as their counterparts in the utility voltage, 


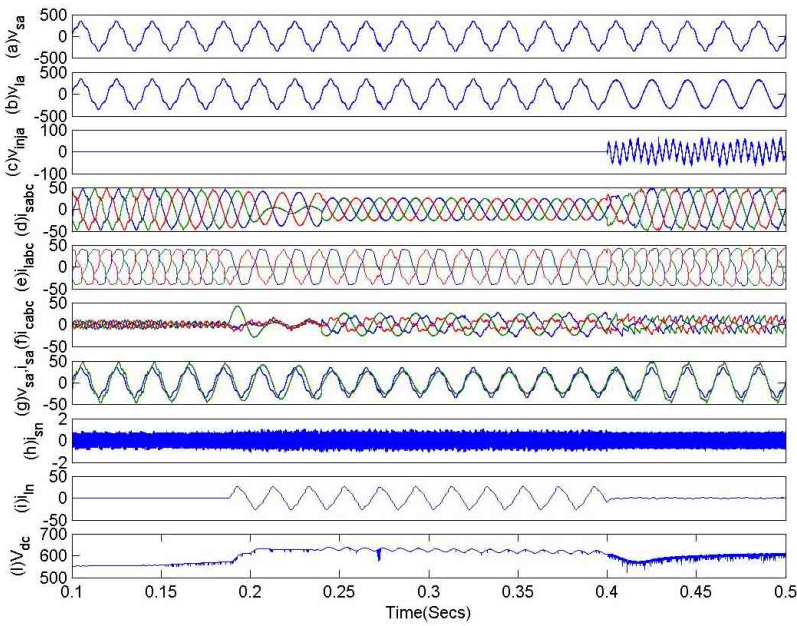

Fig. 4. Dynamic response of UPQC for the compensation of customer generated harmonics only (from $\mathrm{t}=0.1 \mathrm{~s}$ to $\mathrm{t}=0.15 \mathrm{~s}$ ), total source current harmonics only (from $\mathrm{t}=0.15 \mathrm{~s}$ to $\mathrm{t}=0.24 \mathrm{~s}$ ), total source current harmonics and negative sequence components only (from $\mathrm{t}=0.24 \mathrm{~s}$ to $\mathrm{t}=0.32 \mathrm{~s}$ ), total source current harmonics, negative sequence components and reactive power compensation (from $t=0.32 \mathrm{~s}$ to $t=0.50 \mathrm{~s}$ ).

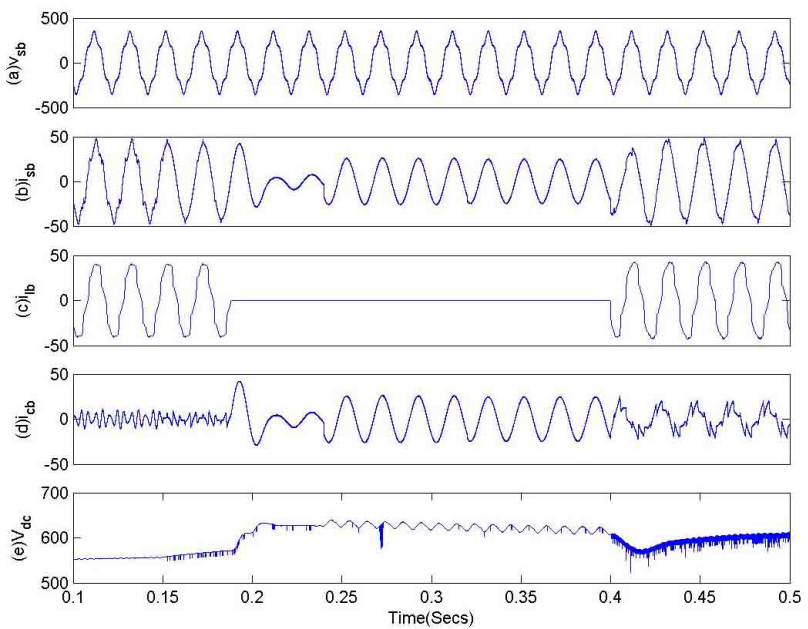

(a)
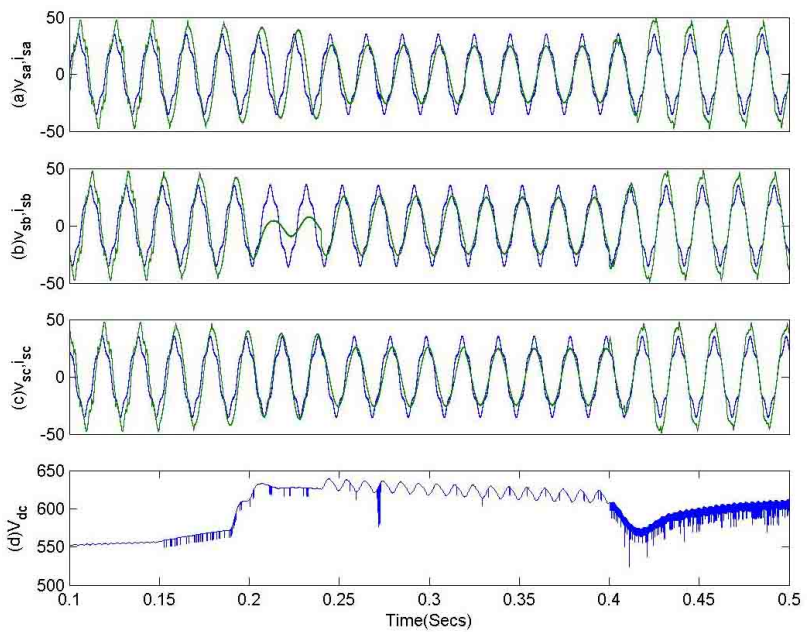

(b)

Fig. 5. Source voltage $\left(v_{s b}\right)$,source current $\left(i_{s b}\right)$,load current $\left(i_{l b}\right)$,Compensator current $\left(i_{c b}\right)$ and DC link voltage $\left(V_{d c}\right)$,(b)source voltage and source current in phase 'a' $\left(v_{s a}, i_{s a}\right)$, source voltage and source current in phase ' $\mathrm{b}$ ' $\left(v_{s b}, i_{s b}\right)$, and source voltage and source current in-phase 'c' $\left(v_{s c}, i_{s c}\right)$ and DC link voltage $\left(V_{d c}\right)$ for customer generated harmonics only, total source current harmonics compensation, total source currents harmonics and negative sequence component compensation and total source currents harmonics, negative sequence component compensation and reactive power compensation, respectively.

which can be mathematically expressed as follows:

$$
i_{\text {conf }}(t)=\sum_{n=1}^{k}\left(\frac{I_{1}}{V_{1}}\right) V_{n} \sin \left(n w t+\theta_{n}+n\left(\phi_{1}-\theta_{1}\right)\right)
$$

where $i_{\text {conf }}(t)$ is the instantaneous value of the conforming current. The difference of conforming and load current, which is equal to the total non-conforming current, will be provided by the shunt APF of UPQC and should be attributable to the customer.

\section{B. Basic Theory of Current Decomposition [14]}

In this control scheme of shunt APF of a three-phase fourwire UPQC, it is proposed to use SRF theory to decompose the load currents instantaneously into active $\left(i_{L 1 R}\right)$ and reactive $\left(i_{L 1 X}\right)$ components of positive and negative sequence of currents $\left(i_{L 1-}\right)$ at fundamental frequency and the harmonic frequencies $\left(i_{L h}\right)$. The SRF isolator extracts the fundamental component of the load by the transformation of $i_{L a}, i_{L b}$ and $i_{L c}$ to the d-q reference frame. In the synchronously rotating reference frame, the positive sequence components at the fundamental frequency $\left(f_{1}\right)$, are transformed into dc quantities and all harmonic and negative frequency components undergo a frequency shift of $f_{1}(=50 \mathrm{~Hz})$.

$$
\begin{gathered}
{\left[\begin{array}{c}
i_{L \alpha} \\
i_{L \beta}
\end{array}\right]=\sqrt{\frac{2}{3}}\left[\begin{array}{ccc}
1 & -\frac{1}{2} & -\frac{1}{2} \\
0 & \frac{\sqrt{3}}{2} & -\frac{\sqrt{3}}{2}
\end{array}\right]\left[\begin{array}{c}
i_{L a} \\
i_{L b} \\
i_{L c}
\end{array}\right]} \\
{\left[\begin{array}{c}
i_{L d+} \\
i_{L q+}
\end{array}\right]=\left[\begin{array}{cc}
\operatorname{Cos}\left(w_{1} t\right) & \operatorname{Sin}\left(w_{1} t\right) \\
-\operatorname{Sin}\left(w_{1} t\right) & \operatorname{Cos}\left(w_{1} t\right)
\end{array}\right]\left[\begin{array}{c}
i_{L \alpha} \\
i_{L \beta}
\end{array}\right] .}
\end{gathered}
$$

The SRF isolator extracts the dc quantities by means of a low-pass filter (LPF) for each $i_{L d}$ and $i_{L q}$, realized by moving average at $100 \mathrm{~Hz}$, since the waveform has a half wave 


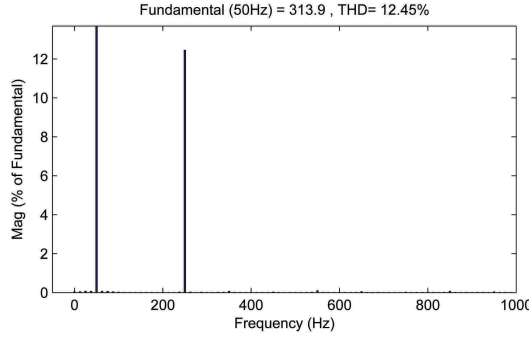

(a)

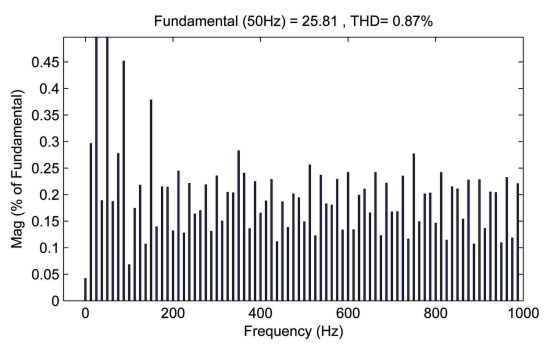

(d)

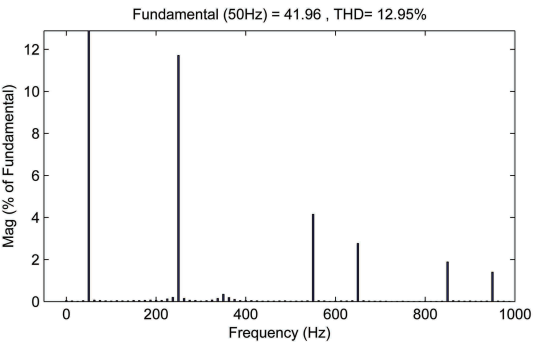

(b)

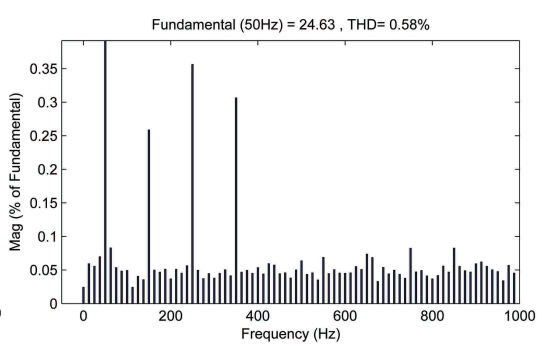

(e)

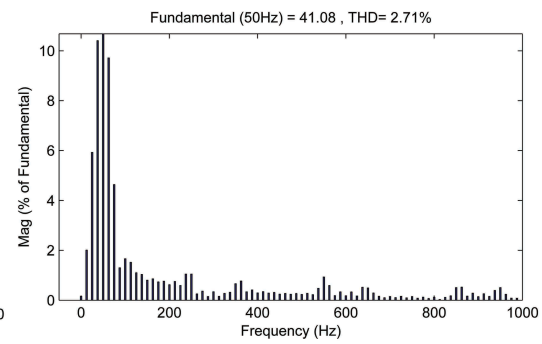

(c)

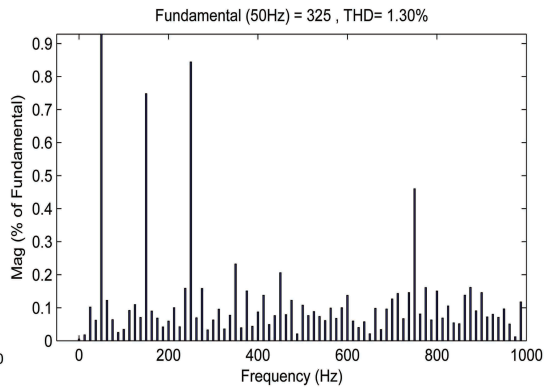

(f)

Fig. 6. (a) THD of source voltage $\left(v_{s a}\right)$, (b)THD of source current $\left(i_{s a}\right)$ during customer generated harmonics only, (c) THD of source current $\left(i_{s a}\right)$ during total source current harmonics only, (d) THD of source current $\left(i_{s a}\right)$ during the mitigation of total source current harmonics and negative sequence components only, (e) THD of source current $\left(i_{s a}\right)$ during the mitigation of total source current harmonics, negative sequence components and reactive power compensation, (f) THD of load voltage $\left(v_{l a}\right)$ after compensation.

symmetry in steady state. The averaged running at $100 \mathrm{~Hz}$ can compute and detect the deviation from the steady state condition within half a cycle. The extracted dc components $i_{L d c D+}$ and $i_{L d c Q+}$ are transformed back into the first $\alpha-\beta$ frame and then into the a-b-c coordinates to obtain the net positive sequence fundamental component as follows:

$$
\left[\begin{array}{c}
i_{L 1 \alpha+} \\
i_{L 1 \beta+}
\end{array}\right]=\left[\begin{array}{cc}
\operatorname{Cos}\left(w_{1} t\right) & -\operatorname{Sin}\left(w_{1} t\right) \\
\operatorname{Sin}\left(w_{1} t\right) & \operatorname{Cos}\left(w_{1} t\right)
\end{array}\right]\left[\begin{array}{c}
i_{L d c D+} \\
i_{L d c Q+}
\end{array}\right]
$$

Where the real and reactive decomposition of the positive sequence fundamental frequency current $\left(i_{L 1 R \alpha+}, i_{L 1 X \beta+}\right)$ can be easily made from the $\mathrm{d}-\mathrm{q}$ frame, thus the $\mathrm{a}-\mathrm{b}-\mathrm{c}$ coordinates of the real and reactive components at the fundamental frequency can be evaluated as detailed in the following:

$$
\begin{aligned}
& {\left[\begin{array}{c}
i_{L 1 R \alpha+} \\
i_{L 1 R \beta+}
\end{array}\right]=\left[\begin{array}{cc}
\operatorname{Cos}\left(w_{1} t\right) & -\operatorname{Sin}\left(w_{1} t\right) \\
\operatorname{Sin}\left(w_{1} t\right) & \operatorname{Cos}\left(w_{1} t\right)
\end{array}\right]\left[\begin{array}{c}
0 \\
i_{L d c Q+}
\end{array}\right]} \\
& {\left[\begin{array}{c}
i_{L 1 X \alpha+} \\
i_{L 1 X \beta+}
\end{array}\right]=\left[\begin{array}{cc}
\operatorname{Cos}\left(w_{1} t\right) & -\operatorname{Sin}\left(w_{1} t\right) \\
\operatorname{Sin}\left(w_{1} t\right) & \operatorname{Cos}\left(w_{1} t\right)
\end{array}\right]\left[\begin{array}{c}
i_{L d c D+} \\
0
\end{array}\right]} \\
& {\left[\begin{array}{c}
i_{L 1 R a+} \\
i_{L 1 R b+} \\
i_{L 1 R c+}
\end{array}\right]=\sqrt{\frac{2}{3}}\left[\begin{array}{cc}
1 & 0 \\
-\frac{1}{2} & \frac{\sqrt{3}}{2} \\
-\frac{1}{2} & -\frac{\sqrt{3}}{2}
\end{array}\right]\left[\begin{array}{c}
i_{L 1 R \alpha+} \\
i_{L 1 R \beta+}
\end{array}\right]} \\
& {\left[\begin{array}{c}
i_{L 1 X a+} \\
i_{L 1 X b+} \\
i_{L 1 X C+}
\end{array}\right]=\sqrt{\frac{2}{3}}\left[\begin{array}{cc}
1 & 0 \\
-\frac{1}{2} & \frac{\sqrt{3}}{2} \\
-\frac{1}{2} & -\frac{\sqrt{3}}{2}
\end{array}\right]\left[\begin{array}{l}
i_{L 1 X \alpha+} \\
i_{L 1 X \beta+}
\end{array}\right]}
\end{aligned}
$$

Similarly for a negative sequence, a fundamental component can be extracted by rotating the frame in the opposite direction, i.e., transformation to the two- phase stationary frame using eqn.(2) after executing the following transformation:

$$
\left[\begin{array}{c}
i_{L d-} \\
i_{L q-}
\end{array}\right]=\left[\begin{array}{cc}
\operatorname{Cos}\left(w_{1} t\right) & -\operatorname{Sin}\left(w_{1} t\right) \\
\operatorname{Sin}\left(w_{1} t\right) & \operatorname{Cos}\left(w_{1} t\right)
\end{array}\right]\left[\begin{array}{l}
i_{L \alpha} \\
i_{L \beta}
\end{array}\right]
$$

and then extracting the dc quantities by a LPF in a similar fashion. The dc quantity would amount to the negative sequence component of the current due to unbalanced voltage at PCC or the unbalanced load condition. The dc components so extracted, $i_{L d c D-}$ and $i_{L d c q-}$ are transformed back into $\alpha-\beta$ frame and then into a-b-c coordinates to obtain the negative sequence fundamental components as follows:

$$
\begin{gathered}
{\left[\begin{array}{l}
i_{L 1 \alpha-} \\
i_{L 1 \beta-}
\end{array}\right]=\left[\begin{array}{cc}
\operatorname{Cos}\left(w_{1} t\right) & \operatorname{Sin}\left(w_{1} t\right) \\
-\operatorname{Sin}\left(w_{1} t\right) & \operatorname{Cos}\left(w_{1} t\right)
\end{array}\right]\left[\begin{array}{l}
i_{L d c D-} \\
i_{L d c Q-}
\end{array}\right]} \\
{\left[\begin{array}{c}
i_{L 1 a-} \\
i_{L 1 b-} \\
i_{L 1 c-}
\end{array}\right]=\sqrt{\frac{2}{3}}\left[\begin{array}{cc}
1 & 0 \\
-\frac{1}{2} & \frac{\sqrt{3}}{2} \\
-\frac{1}{2} & -\frac{\sqrt{3}}{2}
\end{array}\right]\left[\begin{array}{l}
i_{L 1 \alpha-} \\
i_{L 1 \beta-}
\end{array}\right] .}
\end{gathered}
$$

Thus, for selective compensation, the above decomposed components can easily be used.

\section{Control Scheme}

Fig. 3 shows the flow of various control signals and the control scheme based on the various decomposed components. The control scheme depicted in Fig. 3 also incorporates the command for keeping the average dc bus voltage at the back to back VSIs constant or to control it within given limits. The command for the desired compensation of the three-phase supply reference currents $\left(i_{s a}^{*}, i_{s b}^{*}\right.$ and $\left.i_{s c}^{*}\right)$ are derived by taking the difference of the load current and the 
decomposed components using the SRF theory and the nonconforming currents, which need to be compensated. The desired compensation source reference currents are compared to the sensed supply currents $\left(i_{s a}, i_{s b}\right.$ and $\left.i_{s c}\right)$ and are given to a hysteresis current controller to generate the switching signals to the switches of the shunt APF, which makes the supply currents follow its reference values. For the four-leg VSI shunt APF of three-phase four-wire UPQC, the source neutral current is compensated to follow a reference signal of zero magnitude by switching the fourth leg of the VSI, through the hysterisis controller. By doing this, the supply neutral current can be eliminated.

\section{Priority Revolver and Gain Scheduler}

This section describes the calculation of the gains $\left(K_{w}, K_{x}\right.$, $K_{n}, K_{h}$ ) according to the priority assigned to the components needs to be compensated. The level of priority decides the depth of the compensation desired by the system, keeping in view the overloading of the shunt APF by adjustment of the gains $K_{w}, K_{x}, K_{n}$, and $K_{h}$ in reverse order, i.e., a component with a higher priority for its compensation would have a lower gain in the ratio of its priority. The priority of the compensation is fixed on the basis of the severity of ill effects of these decomposed components on the power system. In the proposed scheme for the shunt APF of the UPQC, the first preference has been assigned to the harmonics generated by customers, the total source current harmonics and subsequently the gains of the negative sequence and reactive components are computed, keeping in view the interests of both the consumers and the utility. If it is assumed that the compensation capacity of the shunt APF of the UPQC be limited to $40 \%$ of the total load power, then the maximum value of the sum of the different rms load current components, which can be compensated for, are given as:

$$
\text { Maximum of }\left(I_{n o n-c o n f}+I_{L h}+I_{L 1-}+I_{L 1 X+}\right)=0.4 I_{F L}
$$

where, $I_{F L}$ is rated load current.

\section{RESUltS AND DisCUSSION}

The three-phase four-wire UPQC system and the control strategy of the UPQC are modeled using the MATLAB/SIMULINK enviournment. The load under consideration is a combination of the balanced linear lagging power factor loads and a three-phase diode bridge rectifier with a resistive load on dc side. The unbalance has been created by opening the circuit breaker of phase ' $b$ '. A distortion in the utility voltage is introduced deliberately by injecting $5^{\text {th }}(12.30 \%)$ order voltage harmonics along with the fundamental.

Fig. 4 shows the dynamic performance of the proposed UPQC system under varying load conditions. To visualize the shunt APF and series APF performances individually, both of these are put into operation at different instances of time. The shunt APF is switched on at $t=0.05 \mathrm{sec}$. The first priority of the shunt APF is to compensate for the customer generated harmonics. Therefore, until $\mathrm{t}=0.15 \mathrm{sec}$, the source currents have levels of distortion that are similar to those present in the source voltages as shown in Fig 5(b). The THD in the source voltage is $12.45 \%$, while during the compensation of customer generated harmonics only, the source current THD is $12.95 \%$. This confirms the similar level of distortion in the source current as present in the source voltage. Hence, during the mitigation of customer generated harmonics, the non-linear load behaves as a linear load and the customer is not penalized for distorted supply.

The next priority is the compensation of the total source currents harmonics only. Fig. 4(d) shows that the source currents are balanced and sinusoidal, from $\mathrm{t}=0.15$ to $\mathrm{t}=0.18 \mathrm{sec}$, even under distorted source voltages. The load becomes unbalanced at $\mathrm{t}=0.18 \mathrm{sec}$, by switching off the circuit breaker in phase 'b', as depicted in Fig. 4(e) and Fig. 5(a).Until t=0.24 sec, the shunt APF is only compensating the harmonics of the source currents, hence the source currents are sinusoidal but unbalanced, as shown in Fig. 4(e). They are also lagging w.r.t source voltages in each phase as shown in Fig. 5(b). The next priority of the shunt APF is load balancing, hence, the shunt APF starts compensating the negative sequence components of source currents from $t=0.24 \mathrm{sec}$ onwards. Fig. $4(\mathrm{e})$ shows that the source currents are balanced and sinusoidal after $\mathrm{t}=0.24 \mathrm{sec}$ onwards, but that they are still lagging w.r.t source voltages in each phase as shown in Fig. 5(b). The last priority of the shunt $\mathrm{APF}$ is reactive power compensation, hence the source currents are sinusoidal, balanced and in phase with the corresponding phase voltages, as shown in Fig. 5(b). Fig. 4(e) shows that from $\mathrm{t}=0.15 \mathrm{sec}$ to $\mathrm{t}=0.40 \mathrm{sec}$, the load currents become unbalanced; hence a neutral current flows as shown in Fig. 4(i). The THD of load voltage with and without compensation and source current during mitigation of different components are shown in Fig.6

\section{CONCLUSION}

A new current decomposition technique, based on frequency domain and SRF theory, with indirect current control and reduced number of current sensors for prioritized selective compensation of different power qualities and their combinations has been investigated for the shunt APF of threephase four-wire UPQC. A control strategy based on SRF theory is applied for the control of the series APF of UPQC. The observed performance of the UPQC has demonstrated the ability of the proposed control technique to selectively compensate the customer generated harmonics, the total source current harmonics, unbalanced loading, reactive power and voltage harmonics, based on priority to respect the limited power capacity of VSIs employed for the shunt and series APFs. In addition to this, by mitigation of customer generated harmonics only, the responsibility of the utility and customers at the PCC is attributed. It is also observed that the proposed control scheme has a fast response and is able to maintain the voltage and current harmonics levels, thus conforming to IEEE-519 standards. Further, the applied control scheme is able to self support the dc bus voltage of back to back connected VSIs of the UPQC. The control scheme of shunt APF has the advantage of flexibility in the selection of the power quality indices for which the reference may be computed. In addition to this the shunt APF compensates the 
current based distortions even under distorted utility voltages, hence the operation of shunt and series APF are independent of each other. In case of a voltage sensitive load, the series APF may be switched on to mitigate the voltage harmonics present in the load voltages.

\section{APPENDIX}

The system parameters used are as follows:

Supply voltage and line impedance: $415 \mathrm{~V} \mathrm{~L}-\mathrm{L}, \mathrm{f}=50 \mathrm{~Hz}$, $\mathrm{R}_{\mathrm{s}}=0.1 \Omega, \mathrm{L}_{\mathrm{s}}=0.05 \mathrm{mH}$

Ripple Filter: $\mathrm{R}=7 \Omega, \mathrm{C}=5 \mu \mathrm{F}$

DC bus capacitance: $\mathrm{C}_{\mathrm{dc}}=3000 \mu \mathrm{F}$

DC bus voltage of UPQC: $\mathrm{V}_{\mathrm{dc}}=600 \mathrm{~V}$

Series Transformer: $250 \mathrm{KVA}, 1.1 \mathrm{KV} / 5.5 \mathrm{KV}$

Loads: 1) Three-Phase Rectifier Load with $\mathrm{R}=25 \Omega$ on dc side, and 2) Three single phase load 10KW, 6KVar (lagging) in each phase.

\section{REFERENCES}

[1] A. Ghosh and G. Ledwich, Power Quality Enhancement Using Custom Power Devices, Kulwer International Series in Engineering and Computer Science, 2002.

[2] N. G. Hingorani, "Introducing custom power,"in Proc. IEEE Spectrum, Vol. 32, pp. 41-48, Jun. 1995.

[3] A. Cetin, H.F. Bilgin, A. Acik, T. Demirci, K.N. Kose, A. Terciyanli, B. Gultekin, N. Aksoy, B. Mutluer, I. Çadirci, M. Ermis, K. Ongan, and N. Akinci , "Reactive power ompensation of coal conveyor belt drives by using D-STATCOMs," in Proc. IAS, pp.1731-1740, 2007.

[4] M. J. Newman, D. G. Holmes, J.G. Nielsen, and F. Blaabjerg, "A dynamic voltage restorer (DVR) with selective harmonic compensation at medium voltage level," IEEE Trans. Ind. Appl., Vol. 41, pp.1744-1753, Nov./Dec. 2005.

[5] K. H. Kwan, P. L. So, and Y. C. Chu, "A harmonic selective unified power quality conditioner using MVR with kalman filters," in Proc. IPEC, pp.332-337, 2007.

[6] M. J. Newman and D. G. Holmes, "A universal custom power conditioner (UCPC) with selective harmonic voltage compensation," in Proc. IECON, Vol. 2, pp. 1261-1266, 2002.

[7] H. Akagi, Y. Kanazawa, and A. Nabae, "Generalised theory of the instantaneous reactive power in three-phase circuits," in Proc. IEEE and JIEE IPEC, pp. 821-827, 1983

[8] Y. Komastu and T. Kawabata, "Experimental comparison of p-q and extended p-q methods for active filter," in Proc. EPE, Vol. 2, pp. 2.7292.734, 1997.

[9] M. Depenbork and V. Staut, "The FBD-method as tool for compensating total non-active currents," in Proc. IEEE Harmonics and Quality of Power, pp.320-324, 1998.

[10] L. S. Czarnecki, "Orthogonal decomposition of the currents in a 3-phase nonlinear asymmetrical circuit with a non-sinusoidal voltage source," IEEE Trans. Instrum. Meas., Vol. 37, No. 1, pp. 30-34, Mar. 1998.

[11] F. P. Marafao, S. M. Deckmann, J. A. Pomilio, and R. Q. Machado, "Selective disturbance compensation and comparisons of active filtering strategies," in Proc. IEEE Harmonics and Quality of Power, pp. 484-489, 2002.

[12] B. Singh, V. Verma, and J. Solanki, "Neural network-based selective compensation of current quality problems in distribution systems," IEEE Trans. Ind. Electron., Vol. 54, No. 1, pp. 53-60, Feb. 2007.
[13] H. Karimi, M. Karimi-Ghartemani, M. R. Iravani, and A. R. Bakhshai, "An adaptive filter for synchronous extraction on harmonics and distortions," IEEE Trans. Power Del., Vol. 18, No. 4, pp. 1350-1356, Oct. 2003.

[14] B. Singh and V. Verma, "Selective, compensation of power-quality problems through active power filter by current decomposition" IEEE Trans. Power Del., Vol.23, No.2, pp.792-799, Apr. 2008.

[15] B. Singh and P. Venkateswarlu, "A simplified control algorithm for threephase four-wire unified power quality conditioner," Journal of Power Electronics, Vol. 10, No.1, Jan. 2010.

[16] K. Srinivasan "On separating customer and supply side harmonics contributions," IEEE Trans. Power Del., Vol. 11, pp. 1003-1012, Apr.1996.

[17] S. K. Jain, P. Agarwal, and H. O. Gupta, "A control algorithm for compensation of customer-generated harmonics and reactive power," IEEE Trans. Power Del., Vol. 19, No. 1, Jan. 2004.

[18] S. K. Jain, P. Agarwal, H. O. Gupta, and G. Agnihotri, "Modeling of frequency domain control of shunt active power filter using MATLAB simulink and power system blockset," in Proc. ICEMS, Vol. 2, pp.1124$1129,2005$.

[19] A. M. Alnadi and Y. Liu, "A Shunt power conditioner operated by a simplified version of the gauss-newton algorithm," Int. Journal of Emerging Electric Power Systems, Vol. 11, No. 2, Article. 6, 2010.

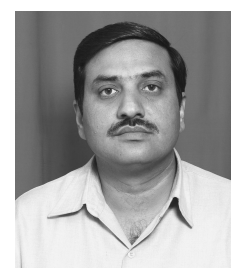

Yash Pal graduated from Madan Mohan Malaviya Engineering College (MMMEC), Gorakhpur, India in 1994 and obtained his M.Tech in Control Systems from the Regional Engineering College, Kurukshetra, India in 1996 . He is currently pursuing his Ph.D. and is an Associate Professor in the Electrical Engineering Department, National Institute of Technology (N.I.T), Kurukshetra, India. His research interests include control applications for electric power distribution systems, power electronics and power quality.

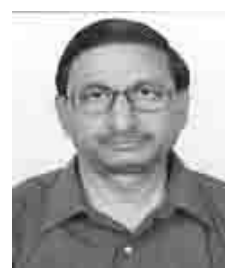

A. Swarup received his Ph.D. in 1993 from the Indian Institute of Technology (IIT), New Delhi, India. He is currently working as Professor in the Department of Electrical Engineering at the National Institute of Technology (N.I.T), Kurukshetra, India. He is a Senior Member of the Institute of Electrical and Electronics Engineers (IEEE). His research interests include robotics and artificial intelligence, system identification, computer networking and control systems.

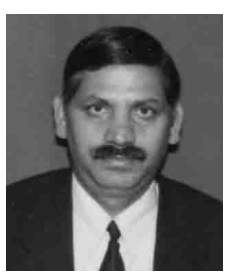

Bhim Singh was born in Rahampur, India, in 1956 He received his B.E. (Electrical) from the University of Roorkee, Roorkee, India, in 1977, and his M.Tech. and Ph.D. from the Indian Institute of Technology (IIT), New Delhi, India, in 1979 and 1983, respectively. In 1983, he joined the Department of Electrical Engineering at the University of Roorkee, as a Lecturer. He became a Reader there in 1988. In December 1990, he joined the Department of Electrical Engineering at the IIT, as an Assistant Professor. He became an Associate Professor in 1994 and a Professor in 1997. He has been a recipient of the JC Bose and the BK Bose awards of the IETE. His current research interests include power electronics, electrical machines and drives, power quality, FACTs and HVDC systems. Professor Singh is a Fellow of the Indian National Academy of Engineering (INAE), the Institution of Engineers (India) (IE (I)), the Institution of Electronics and Telecommunication Engineers (IETE) and IEEE. $\mathrm{He}$ is also a Life Member of the society for Technical Education (ISTE), the System Society of India (SSI), and the National Institute of Quality and Reliability (NIQR). 